University of Wollongong

Research Online

Australian Institute for Innovative Materials -

Papers

Australian Institute for Innovative Materials

$1-1-2016$

Evaluation of persistent-mode operation in a superconducting MgB2 coil in solid nitrogen

Dipakkumar Patel

University of Wollongong, djp485@uowmail.edu.au

Md Shahriar Hossain

University of Wollongong, shahriar@uow.edu.au

Khay Wai W. See

University of Wollongong, kwsee@uow.edu.au

Wenbin Qiu

University of Wollongong,wq118@uowmail.edu.au

Hiroki Kobayashi

University of Wollongong

See next page for additional authors

Follow this and additional works at: https://ro.uow.edu.au/aiimpapers

Part of the Engineering Commons, and the Physical Sciences and Mathematics Commons

Research Online is the open access institutional repository for the University of Wollongong. For further information contact the UOW Library: research-pubs@uow.edu.au 


\title{
Evaluation of persistent-mode operation in a superconducting MgB2 coil in solid nitrogen
}

\begin{abstract}
We report the fabrication of a magnesium diboride (MgB2) coil and evaluate its persistent-mode operation in a system cooled by a cryocooler with solid nitrogen (SN2) as a cooling medium. The main purpose of SN2 was to increase enthalpy of the cold mass. For this work, an in situ processed carbondoped MgB2 wire was used. The coil was wound on a stainless steel former in a single layer (22 turns), with an inner diameter of $109 \mathrm{~mm}$ and height of $20 \mathrm{~mm}$ without any insulation. The two ends of the coil were then joined to make a persistent-current switch to obtain the persistent-current mode. After a heat treatment, the whole coil was installed in the SN2 chamber. During operation, the resultant total circuit resistance was estimated to be $<7.4 \times 10-14 \Omega$ at $19.5 \mathrm{~K} \pm 1.5 \mathrm{~K}$, which meets the technical requirement for magnetic resonance imaging application.
\end{abstract}

\section{Keywords}

solid, evaluation, persistent, mode, operation, superconducting, mgb2, coil, nitrogen

Disciplines

Engineering | Physical Sciences and Mathematics

\section{Publication Details}

Patel, D., Hossain, M. Al., See, K., Qiu, W., Kobayashi, H., Ma, Z., Kim, S., Hong, J., Park, J., Choi, S., Maeda, M., Shahabuddin, M., Rindfleisch, M., Tomsic, M., Dou, S. Xue. \& Kim, J. (2016). Evaluation of persistentmode operation in a superconducting MgB2 coil in solid nitrogen. Superconductor Science and Technology, 29 1-6.

\section{Authors}

Dipakkumar Patel, Md Shahriar Hossain, Khay Wai W. See, Wenbin Qiu, Hiroki Kobayashi, Zongqing Ma, Seong Jun Kim, Jonggi Hong, Jin Yong Park, Seyong Choi, Minoru Maeda, Mohammed Shahabuddin, Matthew A. Rindfleisch, Michael Tomsic, S X. Dou, and Jung Ho Kim 


\title{
Evaluation of persistent-mode operation in superconducting $\mathrm{MgB}_{2}$ coil in solid nitrogen
}

Dipak Patel ${ }^{1}$, Md Shahriar Al Hossain ${ }^{1}$, Khay Wai See ${ }^{1}$, Wenbin Qiu ${ }^{1}$, Hiroki Kobayashi ${ }^{1}$, Zongqing $\mathrm{Ma}^{1}$, Seong Jun Kim${ }^{2}$, Jonggi Hong ${ }^{2}$, Jin Yong Park ${ }^{2}$, Seyong $\mathrm{Choi}^{2}$, Minoru Maeda ${ }^{3}$, Mohammed Shahabuddin ${ }^{4}$, Matt Rindfleisch ${ }^{5}$, Mike Tomsic ${ }^{5}$, Shi Xue Dou ${ }^{1}$, and Jung Ho Kim ${ }^{1}$

${ }^{1}$ Institute for Superconducting and Electronic Materials, Australian Institute for Innovative Materials, University of Wollongong, Squires Way, Innovation Campus, North Wollongong, New South Wales 2519, Australia

${ }^{2}$ Busan Center, Korea Basic Science Institute, Busan 609-735, Republic of Korea

${ }^{3}$ Department of Physics, College of Science and Technology, Nihon University, Tokyo 1018308, Japan

${ }^{4}$ Department of Physics and Astronomy, College of Science, King Saud University, Riyadh 11451, Saudi Arabia

${ }^{5}$ Hyper Tech Research, Inc., 539 Industrial Mile Road, Columbus, Oh 43228, USA

E-mail: jhk@uow.edu.au and sychoi07@kbsi.re.kr

\begin{abstract}
We report the fabrication of a magnesium diboride $\left(\mathrm{MgB}_{2}\right)$ coil and evaluate its persistentmode operation in a system cooled by a cryocooler with solid nitrogen $\left(\mathrm{SN}_{2}\right)$ as a cooling medium. The main purpose of $\mathrm{SN}_{2}$ was to increase enthalpy of the cold mass. For this work, an in-situ processed carbon-doped $\mathrm{MgB}_{2}$ wire was used. The coil was wound on a stainless steel former in a single layer (22 turns), with an inner diameter of $109 \mathrm{~mm}$ and height of 20 $\mathrm{mm}$ without any insulation. The two ends of the coil were then joined to make a persistentcurrent switch to obtain the persistent-current mode. After a heat treatment, the whole coil was installed in the $\mathrm{SN}_{2}$ chamber. During operation, the resultant total circuit resistance was estimated to be $<7.4 \times 10^{-14} \Omega$ at $19.5 \mathrm{~K} \pm 1.5 \mathrm{~K}$, which meets the technical requirement for magnetic resonance imaging application.
\end{abstract}

Keywords: Persistent-mode operation, $\mathrm{MgB}_{2}$, superconducting joint, solid nitrogen, $\mathrm{MRI}$ 


\section{Introduction}

Physicians and surgeons rely critically on magnetic resonance imaging (MRI) scans to diagnose and treat critical injuries and medical conditions. In an MRI system, high, stable $\left(<0.1 \mathrm{ppm} \mathrm{h}{ }^{-1}\right)$, and uniform ( $\leq 10 \mathrm{ppm}$ in $50 \mathrm{~cm}$ diameter of spherical volume (DSV)) magnetic fields are required for obtaining high resolution images of the human body. The unique possibilities for operation of superconducting magnets (i.e., persistent-mode) make them ideal for MRI with a central field strength $>0.35 \mathrm{~T}$ [1]. Thus, in the majority of commercially available MRI systems, superconducting persistent-magnets based on niobium titanium ( $\mathrm{Nb}-\mathrm{Ti}$ ) have been used [2]. These magnets, which are cooled in an expensive liquid helium (LHe) bath at $4.2 \mathrm{~K}$, cannot currently be avoided. Thus, the high operation costs of MRI systems obstruct their extensive use in developing and underdeveloped countries [3].

To fulfil the above requirements, the magnesium diboride $\left(\mathrm{MgB}_{2}\right)$ magnet, which can be operated at around $20 \mathrm{~K}$ in an LHe-free manner, is considered as one of the best potential candidates for next-generation MRI application [4, 5]. It has been reported that the heat capacity of $\mathrm{MgB}_{2}$ magnets can be significantly enhanced by cooling them using solid nitrogen $\left(\mathrm{SN}_{2}\right)$ with a cryocooler [6]. The high heat capacity of $\mathrm{SN}_{2}$ is well known to enable a magnet to operate for a certain time period in the absence of a cooling source (i.e., cryocooler) [7], which is suitable for areas where power failure is common. Takahashi et al reported the first successful persistent-mode coil with joints between $\mathrm{MgB}_{2}$ and $\mathrm{Nb}-\mathrm{Ti}$ wires [8]. Jiayin et al reported the operating results for $\mathrm{MgB}_{2}$ persistent-mode coils in a helium environment [9]. Nardelli et al also reported on persistent-mode operation with a short $\mathrm{MgB}_{2}$ tape winding operating with conduction cooling [10]. Until now, however, there have been no reports on persistent-mode operation in an $\mathrm{SN}_{2}$ cooled system with an $\mathrm{MgB}_{2}$ coil.

In this paper, the fabrication of an $\mathrm{MgB}_{2}$ coil and its persistent-current switch (PCS), a newly developed $\mathrm{SN}_{2}$ cooling system, and the operation of the coil in persistent-mode are presented in detail.

\section{Experimental details}

Hyper Tech Research Inc. supplied monofilamentary carbon-doped $\mathrm{MgB}_{2}$ wire (strand no. 3356) for the coil. The wire was $0.84 \mathrm{~mm}$ in diameter, constructed with an $\mathrm{MgB}_{2}$ filament (diameter $-0.4 \mathrm{~mm}$ ), a niobium inner barrier (thickness $-0.10 \mathrm{~mm}$ ) and a Monel outer 
sheath (thickness - $0.12 \mathrm{~mm}$ ). Figure $1(\mathrm{a})$ presents a digital photograph of the coil, which was fabricated via the wind and react method with a heat treatment at $690{ }^{\circ} \mathrm{C}$ for $30 \mathrm{~min}$ in argon (Ar) atmosphere. The whole coil was assembled with the main $\mathrm{MgB}_{2}$ coil at the bottom and the PCS at the top. The PCS was made by extending the two ends of the coil and joining them together. The diameter of the PCS was $113.5 \mathrm{~mm}$ with two non-inductively wound turns, and its estimated wire resistance $\sim 7.1 \mathrm{~m} \Omega \mathrm{m}^{-1}$ at $40 \mathrm{~K}$. The inner diameter and the height of the coil were $109 \mathrm{~mm}$ and $20 \mathrm{~mm}$, respectively. The coil was wound in a single layer (22 turns) without any insulation. The calculated inductance of the coil was $86.7 \pm 0.02$ $\mu \mathrm{H}[11]$.

The joining process developed at the University of Wollongong include [12]: (i) etching the Monel from the area of the wires to be joined, (ii) polishing the ends of the two wires until the $\mathrm{MgB}_{2}$ core was exposed, (iii) aligning the two wires together using glue, (iv) mounting the two wires in a stainless steel (SS) enclosure using a high temperature sealing material, ( $v$ ) packing the $\mathrm{Mg}+2 \mathrm{~B}$ composite powder in the SS enclosure in Ar atmosphere, (vi) pressing the powder using SS plug, and (vii) sealing the remaining gaps using a high temperature sealing material.

(a)

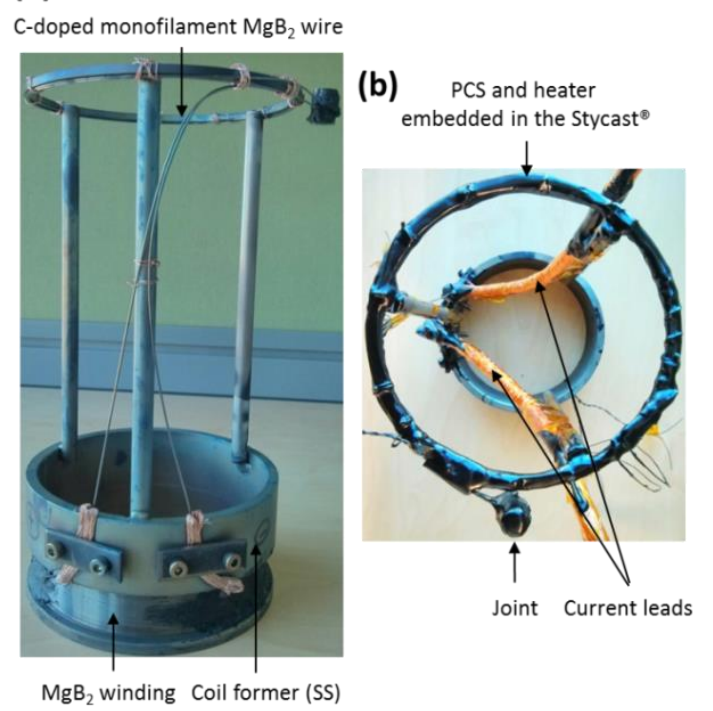

Figure 1. (a) Digital photograph of the fabricated coil after heat treatment, (b) top view of the coil after applying Stycast $^{\circledR} 2850$ FT (Catalyst 9) epoxy.

To charge the current into the main coil, the PCS was needed to be heated up to resistive state. This was achieved using a $47 \Omega$ Nichrome heater (Lakeshore, 32 AWG) wound on the PCS. Copper $(\mathrm{Cu})$ current leads were installed between the PCS and the coil. Three pairs of 
voltage taps were attached, one each from the coil, the PCS, and the joint, to monitor the voltage drops during charging of the coil. A top view of the coil after applying epoxy encapsulant Stycast ${ }^{\circledR}$ is shown in figure $1(b)$.
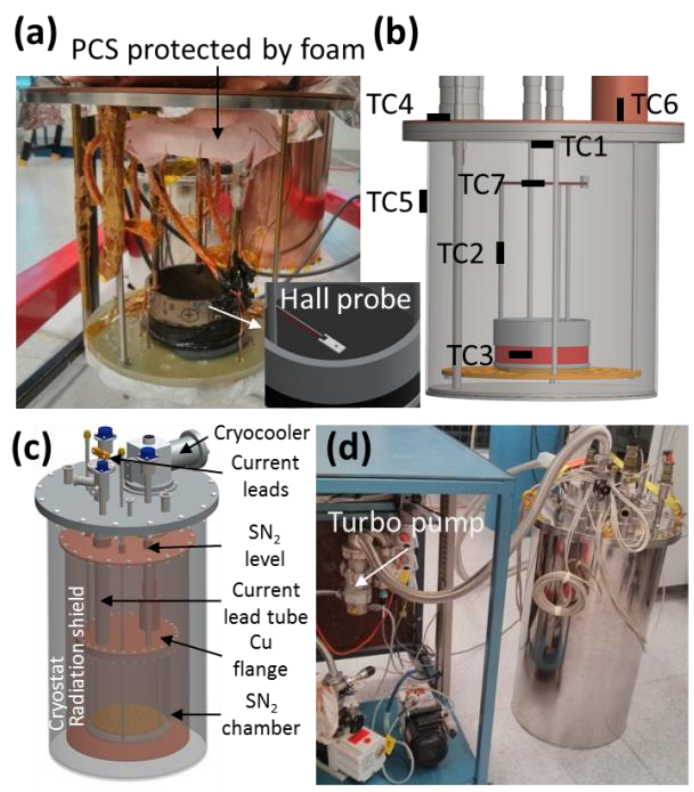

Figure 2. (a) Photograph of the installed coil in the $\mathrm{SN}_{2}$ chamber, with a 3D model of the Hall probe location (the centre of the coil at $z=0$ ) shown in the inset; $(b)$ schematic diagram of the temperature sensor locations (TC1 - at the top of the $\mathrm{SN}_{2}$ chamber (inside), $\mathrm{TC2}-$ at the centre, between the coil and the PCS, TC3 - at the coil winding, TC4 - on top of the $\mathrm{SN}_{2}$ chamber near the current lead tube, TC5 $-100 \mathrm{~mm}$ below the top collar of the $\mathrm{SN}_{2}$ chamber, TC -6 , at the bottom of the Cu bar below the cryocooler, TC7 - at the PCS); (c) 3D model of the $\mathrm{SN}_{2}$ cooling system, and (d) photograph of the experimental set-up.

Figure 2(a) shows the coil installed in the $\mathrm{SN}_{2}$ chamber. Prior to installing the whole coil in the $\mathrm{SN}_{2}$ chamber, the PCS was covered with expanded polyethylene (EPE) foam to enable easy temperature control under the $\mathrm{SN}_{2}$ for charging the coil. A Hall probe with $0.1 \mathrm{G}$ sensitivity was installed at the centre of the coil to detect the magnetic field $(B)$ generated by the coil (figure 2(a) inset). Seven cryogenic temperature sensors were also installed to monitor the temperatures of the $\mathrm{SN}_{2}$ chamber and the coil, as shown in figure 2(b). Figure 2(c) shows a three-dimensional (3D) model of the $\mathrm{SN}_{2}$ cooling system. The GiffordMcMahon two-stage cryocooler (Sumitomo, RDK-408D2) was used in the cooling system featuring $1^{\text {st }}$ stage cooling capacity of $40 \mathrm{~W}$ at $43 \mathrm{~K}$ and $2^{\text {nd }}$ stage of $1 \mathrm{~W}$ at $4.2 \mathrm{~K}$. Figure $2(\mathrm{~d})$ shows the assembled $\mathrm{SN}_{2}$ cooling system. 


\section{Results and discussion}

To cool down the coil in $\mathrm{SN}_{2}$, the system was first evacuated using a turbo vacuum pump (figure 2(d)). The $\mathrm{SN}_{2}$ chamber was mechanically sealed using indium wire. A vacuum of $<2 \times$ $10^{-6}$ torr in the system was achieved, and then liquid nitrogen $\left(\mathrm{LN}_{2}\right)$ was introduced into the $\mathrm{SN}_{2}$ chamber. When the temperature at TC6, as shown in figure $2(\mathrm{~b})$, reached $280 \mathrm{~K}$, the cryocooler was switched on. The purpose of the early switching on of the cryocooler was to avoid the rapid evaporation of $\mathrm{LN}_{2}$. Once the $\mathrm{SN}_{2}$ chamber was fully filled with $\mathrm{LN}_{2}$, both the inlet and the outlet were closed, and a non-return valve was installed. The temperature of the radiation shield remained at $36 \mathrm{~K}$ throughout the experiment.

Figure 3 shows the temperature profiles of the $\mathrm{SN}_{2}$ chamber during the system cool down. The total volume of $\mathrm{SN}_{2}$ in the chamber was about $16 \mathrm{~L}$. It took about 4.56 days to reach the minimum temperature of $7.2 \mathrm{~K}$ in the $\mathrm{SN}_{2}$ chamber, whereas the temperature on the $2^{\text {nd }}$ stage of the cryocooler reached $4.85 \mathrm{~K}$. Liquid to solid, and solid to solid phase transitions were observed at $\sim 63 \mathrm{~K}$, and $\sim 35.6 \mathrm{~K}$, respectively. The level of the $\mathrm{SN}_{2}$ in the chamber reached up to the radiation shield flange (see figure 2(c)). Thus, additional heat conduction was taking place from the $\mathrm{SN}_{2}$ in the current lead and the $\mathrm{SN}_{2}$ in the tubes running into and out of the chamber. This might have prevented the $\mathrm{SN}_{2}$ chamber from cooling down to the cryocooler $2^{\text {nd }}$ stage temperature. The temperature inside the $\mathrm{SN}_{2}$ chamber remained uniform at around $7.4 \mathrm{~K} \pm 0.2 \mathrm{~K}$. However, the temperatures at the TC4 and TC5 locations were around $11.1 \mathrm{~K}$ and $10.2 \mathrm{~K}$, respectively. This clearly indicates the high conductive heat load from the current lead tube (with $\mathrm{SN}_{2}$ ) to the $\mathrm{SN}_{2}$ chamber. In fact, prior to fabricating this system, our finite element method (FEM) simulation predicted similar behaviour even without $\mathrm{SN}_{2}$ in the current lead tube. The temperature gradient might be due to the lower thermal conductivity of the SS material of the $\mathrm{SN}_{2}$ chamber. Owing to this, the cryocooler was unable to absorb heat from the far end of the $\mathrm{SN}_{2}$ chamber. Thus, a $3 \mathrm{~mm}$ thick $\mathrm{Cu}$ flange was placed on the top of the $\mathrm{SN}_{2}$ chamber (see figure. 2(c)). As a result, the FEM simulation showed a negligible temperature gradient after installing the $\mathrm{Cu}$ flange on top of the $\mathrm{SN}_{2}$ chamber.

However, during actual cool down, due to the high conductive heat load through the $\mathrm{SN}_{2}$ in the current lead tube, the cryocooler (when at $4.85 \mathrm{~K}$ ) was unable to absorb heat from the far end of the $\mathrm{SN}_{2}$ chamber, which left a temperature gradient on top of the $\mathrm{SN}_{2}$ 
chamber. On the other hand, when the temperature of the $\mathrm{SN}_{2}$ chamber was controlled to around $18 \mathrm{~K}$, the temperature gradient in entire $\mathrm{SN}_{2}$ chamber was reduced to $\sim 1.75 \mathrm{~K}$ (not shown here), which indicates that the $\mathrm{Cu}$ flange facilitated better heat conduction to the cryocooler.

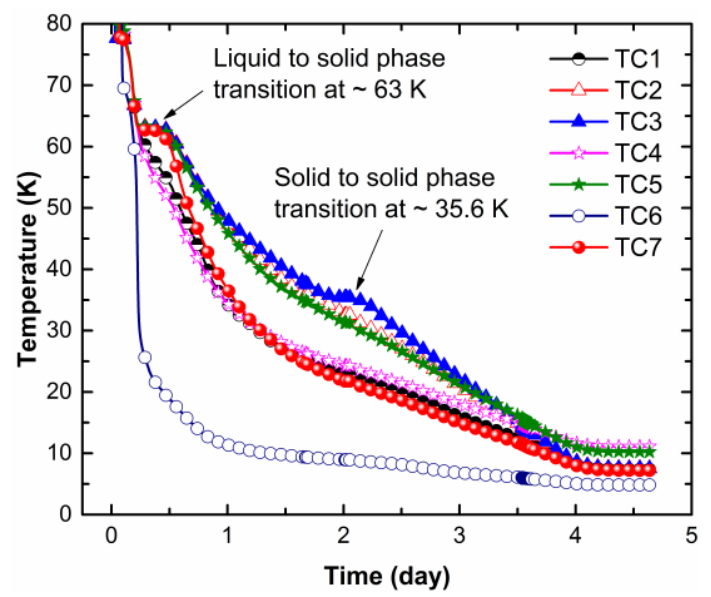

Figure 3. Temperature vs. time profiles during cool down of the $\mathrm{SN}_{2}$ chamber.

(a)

(b)
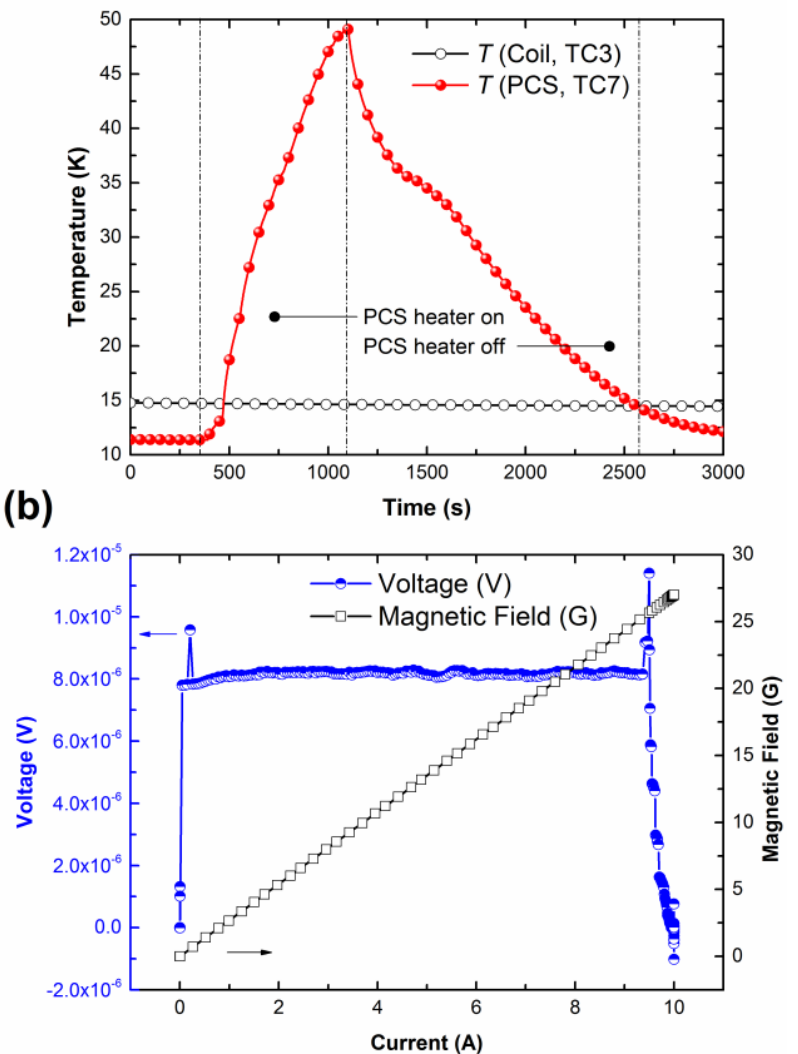

Figure 4. (a) Temperature vs. time profile during open/closed operation of PCS, TC3 - at the coil winding, TC7 - at the PCS, and (b) voltage and magnetic field vs. current profiles while charging the coil when the PCS was open. 


\section{PCS testing}

The on/off function of the PCS was evaluated at the PCS temperature of $11.3 \mathrm{~K}$. As can be seen in figure 4(a), the PCS reached $45 \mathrm{~K}$ in $600 \mathrm{~s}$. The heater power was $3 \mathrm{~W}$. Once the PCS temperature climbed above $45 \mathrm{~K}$, the coil was charged with a ramp rate of $0.1 \mathrm{~A} \mathrm{~s}^{-1}$ up to 10 A. As can be seen in the figure $4(b), B$ at the centre of the coil was increasing linearly with the current. At $10 A$, the $B$ at the centre of the coil was 27 gauss (G), which matched the calculated value of $24.8 \mathrm{G}$. The variation in $B$ might be due to misalignment of the Hall probe. During current charging, the inductive voltage was about $8.17 \pm 0.12 \mu \mathrm{V}$, which is comparable to the $81.7 \pm 1.2 \mu \mathrm{H}$ inductance of the coil. This value is well matched with the calculated inductance of $86.7 \pm 0.02 \mu \mathrm{H}$. After reaching $10 \mathrm{~A}$, the PCS heater was switched off. It took about $1480 \mathrm{~s}$ to cool down the PCS. The reasons for the longer PCS cool down time might be due to over-protection of the PCS, contact between the $\mathrm{SN}_{2}$ and the PCS (solid phase transition can be seen in figure 4(a)), and lower thermal conduction through the SS bars (see figure 1) from the surroundings to cool the PCS back down to the initial temperature.
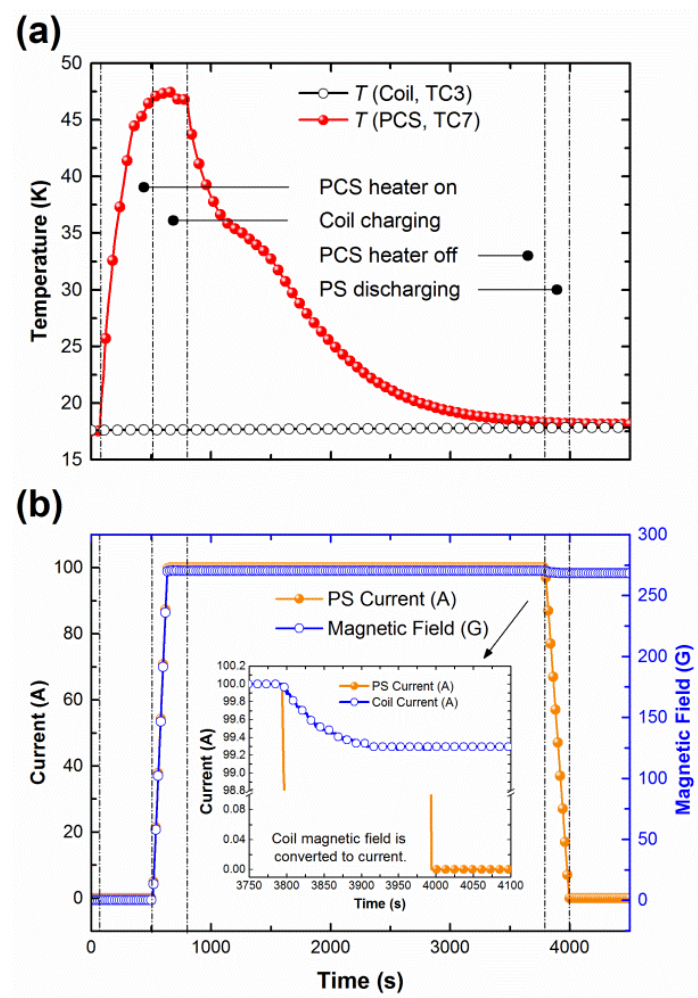

Figure 5. Measurements when the coil was put into persistent-mode at $100 \mathrm{~A}$ : (a) temperature vs. time (Coil and PCS) profiles, TC3 - at the coil winding, TC7 - at the PCS, (b) 
current and magnetic field vs. time profiles (inset: magnified plot of the current vs. time plot while discharging the PS (coil magnetic field was converted to current)).

\section{Persistent-mode coil testing at $100 \mathrm{~A}$}

The temperature of the coil and the PCS was fixed at around $18 \mathrm{~K}$ prior to charging the coil. As can be seen in figure 5(a), firstly, the temperature of the PCS was increased above 45 $\mathrm{K}$, and the coil was charged to $100 \mathrm{~A}$ with a ramp rate of $0.5 \mathrm{~A} \mathrm{~s}^{-1}$ (figure $5(\mathrm{~b})$ ). As can be seen in figure 5(b), we waited for about $140 \mathrm{~s}$ and confirmed the coil constant prior to switching off the PCS heater. It took about $3000 \mathrm{~s}$ to cool down the PCS. The enthalpy of the material increases at high temperature [11], thus the PCS cooling time was longer at $18 \mathrm{~K}$ compare to PCS cooling time at $11.3 \mathrm{~K}$ during PCS testing at $10 \mathrm{~A}$. Then, the power supply (PS) was discharged with a ramp-down rate of $0.5 \mathrm{~A} \mathrm{~s}^{-1}$. To check the initial decay generated by the coil while discharging the PS current, the $B$ in the coil was converted to current using the coil constant. The inset in figure $5(b)$ shows the magnified profiles of the current vs. time while discharging the PS. Herein, the coil current initially decayed by about $0.7 \mathrm{~A}$, and then remained stable at 99.3 A. Decay in the current showed exponential behaviour. The initial decay might be due to the phenomenon of 'settling' of current in closed superconducting circuit [13].

As a result, the coil was kept in the persistent-current mode for about 4.75 days. Figure $6(a)$ and (b) shows the $B$ and temperature profiles in the coil for the entire persistent-mode duration. In figure $6(\mathrm{a}), B$ was observed to remain around $268.4 \mathrm{G}$ with $\pm 0.1 \mathrm{G}$ fluctuation, but without any noticeable decay within the resolution limit of a gauss meter. This fluctuation might be due to the data acquisition instrument. During persistent-mode operation, the joint experienced only self-field with very small influence (2.5 G) from the main coil. The temperature of the coil and the PCS was then increased up to $21 \mathrm{~K}$ and $20.6 \mathrm{~K}$, respectively (figure $6(\mathrm{~b})$ ). If we consider $0.1 \mathrm{G}$ (resolution limit) decay of $B$ in the coil in 4.75 days, the calculated total circuit resistance would be $<7.4 \times 10^{-14} \Omega$ at $19.5 \mathrm{~K} \pm 1.5 \mathrm{~K}$. The $B$ line calculated from the $R L$ circuit time constant corresponding to the minimum measurable resistance of $7.4 \times 10^{-14} \Omega$ over the 4.75 days is also included in figure $6(a)$. We further need to consider the effect of $n$-value, indicating a joint quality. It has been reported that the circuit resistance strongly depends on the $n$-value and joint resistance [11]. Especially, low 
$n$-values make the persistent-mode impossible [14]. Later, the PCS was charged to $200 \mathrm{~A}$ without any quench at $20 \mathrm{~K}$. During the attempt to charge the coil to $200 \mathrm{~A}$, a quench occurred when the charging current was $183 \mathrm{~A}$, which damaged the coil. This incident prevented us from carrying out any further experiments. Moreover, in future test, we will implement quench protection system in the experiment to avoid damage to the coil while charging at the higher current.
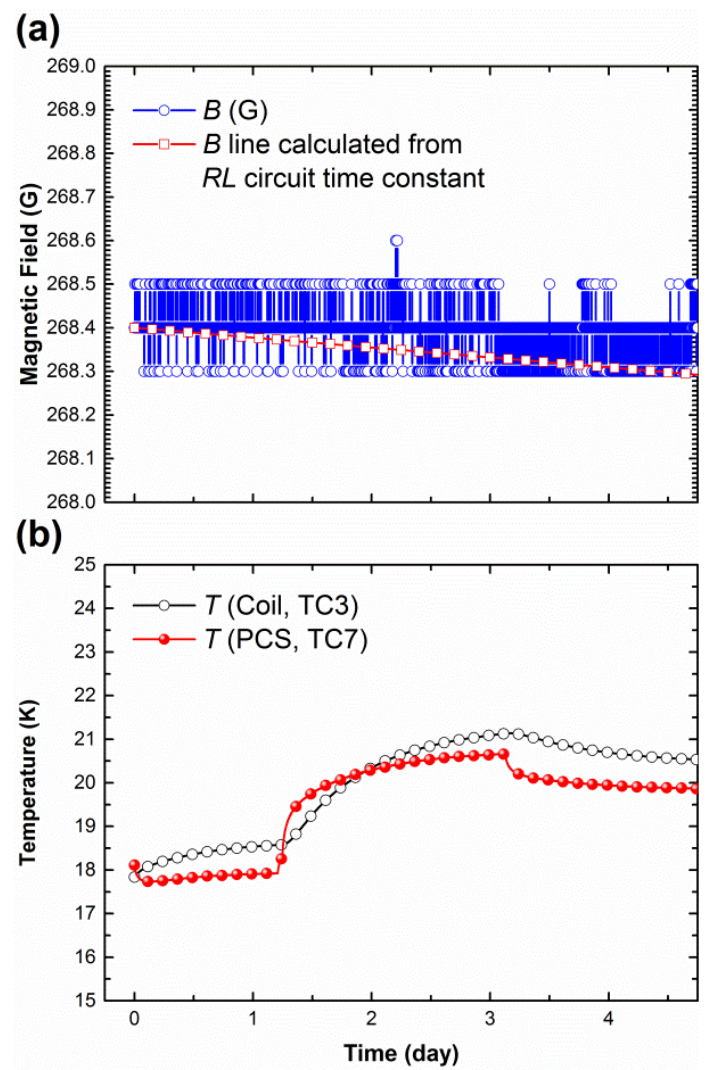

Figure 6. Measurements after putting the coil into persistent-mode: (a) magnetic field vs. time profile of the coil including $B$ line calculated from $R L$ circuit time constant, and (b) temperature vs. time (Coil and PCS, TC3 - at the coil winding, TC7 - at the PCS).

\section{Conclusion}

The $\mathrm{MgB}_{2}$ coil and the PCS were successfully fabricated through a superconducting-joint technique, and the persistent-current mode of the system was evaluated with $\mathrm{SN}_{2}$ cooling and a $100 \mathrm{~A}$ operating current. The total circuit resistance was estimated to be $<7.4 \times 10^{-14} \Omega$ at $19.5 \mathrm{~K} \pm 1.5 \mathrm{~K}$, in the coil during reasonably long-term persistent-mode operation for 4.75 days. This performance is comparable to the technical requirement for practical MRI 
application. This joining technique will be further optimized for multifilament $\mathrm{MgB}_{2}$ conductors in the near future.

\section{Acknowledgments}

The authors would like to thank Dr. John Voccio of the Massachusetts Institute of Technology for helpful discussion. This work was supported by the Australian Research Council (FT110100170, DE130101247), University of Wollongong and Australian Institute for Innovative material internal grant, the Korea Basic Science Institute grant number C36222, JSPS KAKENHI grant number 26709021, Deanship of Scientific Research at King Saud University research group project number RGP- VPP-290, and Hyper Tech Research Inc., USA.

\section{References}

[1] Cosmus T C and Parizh M 2011 Advances in whole-body MRI magnets IEEE Trans. Appl. Supercond. 21 2104-9

[2] Lvovsky Y, Stautner E W and Zhang T 2013 Novel technologies and configurations of superconducting magnets for MRI Supercond. Sci. Technol. 26093001

[3] Kara D C 2013 Production of a viable product in magnetic resonance imaging using $\mathrm{MgB}_{2}$. Master thesis, Case Western Reserve University, 2013

[4] Modica M, Angius S, Bertora L, Damiani D, Marabotto M, Nardelli D, Perrella M, Razeti M and Tassisto $M 2007$ Design, construction and tests of $\mathrm{MgB}_{2}$ coils for the development of a cryogen free magnet IEEE Trans. Appl. Supercond. 17 2196-9

[5] Mine S, Song H, Xu M, Marte J, Buresh S, Stautner W, Immer C, Laskaris E T and Amm K 2012 Test coil for the development of a compact $3 \mathrm{~T} \mathrm{MgB}_{2}$ magnet IEE Trans. Appl. Supercond. 22 4

[6] Bascuñán J, Lee H, Bobrov E S, Hahn S, Iwasa Y, Tomsic M and Rindfleisch M 2006 A 0.6 $\mathrm{T} / 650 \mathrm{~mm} \mathrm{RT}$ bore solid nitrogen cooled $\mathrm{MgB}_{2}$ demonstration coil for MRI - A status report IEEE Trans. Appl. Supercond. 16 1427-30

[7] Yao W, Bascuñán J, Kim W S, Hahn S, Lee H and Iwasa Y 2008 A solid nitrogen cooled $\mathrm{MgB}_{2}$ "demonstration" coil for MRI applications IEEE Trans. Appl. Supercond. 18 912-5

[8] Takahashi M, Tanaka K, Okada M, Kitaguchi H and Kumakura H 2005 Relaxation of a trapped magnetic field in a $100 \mathrm{~m}$ long class MgB2 solenoid coil in persistent current mode operation Supercond. Sci. Technol. 18 S373-S5

[9] Jiayin L, Voccio J P, Seungyong H, Youngjae K, Jungbin S, Juan B and Iwasa Y 2015 Construction and persistent-mode operation of $\mathrm{MgB}_{2}$ coils in the range $10-15 \mathrm{~K}$ for a 0.5 T/240-mm cold bore MRI magnet IEEE Trans. Appl. Supercond. 25 1-5

[10] Nardelli D, Angius S, Capelluto A, Damiani D, Marabotto R, Modica M, Perrella M and Tassisto M 2010 Persistent mode MgB $_{2}$ short windings IEEE Trans. Appl. Supercond. 20 19982001

[11] Iwasa Y 2009 Case studies in superconducting magnets, design and operation issues (New York: Springer)

[12] Patel D, Hossain M S A, See K W, Xu X, Barua S, Ma Z, Choi S, Tomsic M and Kim J H 2015 $\mathrm{MgB}_{2}$ superconducting joints for persistent current operation Supercond. Sci. Technol. 28 065017 
[13] Brittles G D, Mousavi T, Grovenor C R M, Aksoy C and Speller S C 2015 Persistent current joints between technological superconductors Supercond. Sci. Technol. 28093001

[14] Patel D, Hossain M S A, Motaman A, Barua S, Shahabuddin M and Kim J H 2014 Rational design of $\mathrm{MgB}_{2}$ conductors toward practical applications Cryogenics 63 160-5 